\title{
Coal char oxidation kinetics in air medium
}

\author{
Alexander G. Korotkikh ${ }^{1}$, Konstantin V. Slyusarskiy, ${ }^{1, *}$, and Ivan V. Sorokin ${ }^{1}$ \\ ${ }^{1}$ National ResearchTomsk polytechnic university, 634050 Tomsk, Russia
}

\begin{abstract}
Study of oxidation kinetics for three types of coal char with different carbon content in air is presented. The coal char powders of anthracite, bituminous T-grade coal and 2B-grade lignite with particle size less than $80 \mu \mathrm{m}$ were tested. The coal char oxidation was researched by isothermal method via simultaneous TG-DSC analyzer Netzsch STA 449 Jupiter F3 in the temperature range of $1000-1200{ }^{\circ} \mathrm{C}$. Measurements were carried out at ambient pressure. Volumetric flow rate of oxidizing medium into analyser chamber was $250 \mathrm{ml} / \mathrm{min}$. Flow consisted of air and argon with volumetric ratio 24/1. Carbon average rate of oxidation reaction at each temperature were defined based on experimental results. Kinetic constants (the frequency factor and activation energy) were defined for Arrhenius equation modified with three submodels: volumetric model, shrinking core model and random pore model. The activation energy values for anthracite are 1,6-1,7 times higher than for chars of bituminous coal and lignite.
\end{abstract}

\section{Introduction}

Recently, the increased attention is paid to solid fuel conversion, in particular, for bituminous coals and lignite [1]. This data is used to improve combustion characteristics on thermal power plants and to produce syngas and hydrogen for chemical and metallurgical industry via gasification $[1,2]$. Solid fuel gasification on thermal power plant would allow to resolve problem of environment pollution and utilization of flue gases which are formed in traditional combustion equipment. Thermochemical process of solid fuel gasification is carried out to obtain combustible gases $\left(\mathrm{H}_{2}, \mathrm{CO}, \mathrm{C}_{\mathrm{n}} \mathrm{H}_{\mathrm{m}}\right)$ and realized during interaction of fixed carbon with different oxidizers. The air, oxygen, steam, carbon dioxide or their mixtures are used as oxidizing medium [3]. Depending on feed content, process temperature, fuel residence time and other factors the different syngas with needed characteristics could be obtained.

Solid fuel gasification is realized in gasifyers with gaseous oxidizer feed there the main heterogeneous reactions takes place, mainly, carbon oxidizing by steam, carbon dioxide and oxygen resulted in hydrogen, carbon monoxide and dioxide formation [4]. Modern gasification technologies apply two-staged approach [5] there processes of oxidizing and reduction are takes place in different chambers of gasifyer. This defines increased interest for carbon oxidation reaction kinetics:

$$
\mathrm{C}+\mathrm{O}_{2}=\mathrm{CO}_{2} \text {. }
$$

*Corresponding author: konstantinsv@tpu.ru 
Experimental research on solid fuel gasification process as well as heterogeneous carbon reactions with air is further important as long as this reaction is closely connected to heterogeneous reactions of carbon with carbon dioxide and steam:

$$
\begin{gathered}
\mathrm{C}+\mathrm{CO}_{2}=2 \mathrm{CO}, \\
\mathrm{C}+\mathrm{H}_{2} \mathrm{O}=\mathrm{CO}+\mathrm{H}_{2}, \\
\mathrm{C}+2 \mathrm{H}_{2} \mathrm{O}=\mathrm{CO}_{2}+2 \mathrm{H}_{2} .
\end{gathered}
$$

The thermal analysis results of three coal chars of Kuznetsk and Kansk-Achinsk deposits in air medium in temperature range $1000-1200{ }^{\circ} \mathrm{C}$. Based on experimental results the mass loss rate values were defined as well as gasification times. The kinetic constants activation energy and frequency factor - for process were defined using Arrhenius equation and three kinetic submodels: volumetric model, shrinking-core model and random pore model. The activation energy dependence on fixed-carbon content in fuel is presented as well.

\section{Experimental section}

\subsection{Solid Fuel Characteristics}

The powders with particle size less than $80 \mu \mathrm{m}$ of three different coal chars were used in current research. Fixed-carbon content in initial samples was defined by total mass loss rate during heating of the sample in oxidizing medium. Density of studied solid fuel samples was measured by picnometric method. Density and fixed carbon content of studied samples

\begin{tabular}{|c|c|c|c|}
\hline Solid fuel sample & $\begin{array}{c}\text { Specific density, } \\
\mathrm{kg} / \mathrm{m}^{3}\end{array}$ & $\begin{array}{c}\text { Poured density, } \\
\mathrm{kg} / \mathrm{m}^{3}\end{array}$ & $\begin{array}{c}\text { Fixed carbon } \\
\text { content, wt. \% }\end{array}$ \\
\hline Anthracite & $1753 \pm 56$ & $339 \pm 2$ & 89 \\
\hline Bituminous coal & $1927 \pm 15$ & $340 \pm 6$ & 74 \\
\hline Lignite & $1425 \pm 10$ & $347 \pm 13$ & 66 \\
\hline
\end{tabular}
presented in table 1 .

Table 1. Density and fixed carbon content of solid fuel samples.

\subsection{Thermal Analysis}

The studied solid fuel samples were undergo pyrolysis by heating in SNOL 30/1100 in nitrogen atmosphere with $50{ }^{\circ} \mathrm{C} / \mathrm{min}$ rate to $1000{ }^{\circ} \mathrm{C}$ to obtain coal char, remove humid and volatile matter from initial fuel. Solid fuel with $20 \mathrm{~g}$ mass were put into ceramic crucible and held in furnace for one hour and then cooled to $400{ }^{\circ} \mathrm{C}$. Thermal analysis of obtained coal char samples with $20 \mathrm{mg}$ mass was carried out via simultaneous TG-DSC analyzer Netzsch STA 449 F3 Jupiter. Studied coal char were heated in analyzer chamber in argon medium with $50{ }^{\circ} \mathrm{C} / \mathrm{min}$ heating rate to temperatures 1000,1100 and $1200{ }^{\circ} \mathrm{C}$. Argon volumetric flow rate was $10 \mathrm{ml} / \mathrm{min}$. After reaching the preset temperature the inert medium in furnace was changed on argon-air mixture with volumetric ratio 24/1. The oxidizing medium flow rate was $250 \mathrm{ml} / \mathrm{min}$. to eliminate diffusional effects on process. The isothermal soaking time for coal char samples for studying carbon oxidation varied from 50 to $80 \mathrm{~min}$.

\section{Results and discussion}


TG-data on studied samples in air medium are presented in form of thermographs in fig. 1.

During coal char heating to preset temperature in argon the sample mass loss varied from 4 to $7 \mathrm{wt}$ \% depending on initial mass and fuel grade. After hot air inlet into heated furnace the exothermal carbon oxidation reactions were registered and coupled by sample mass loss for $73 \mathrm{wt}$ \% for anthracite and bituminous coal char and $85 \mathrm{wt}$. \% for lignite char.
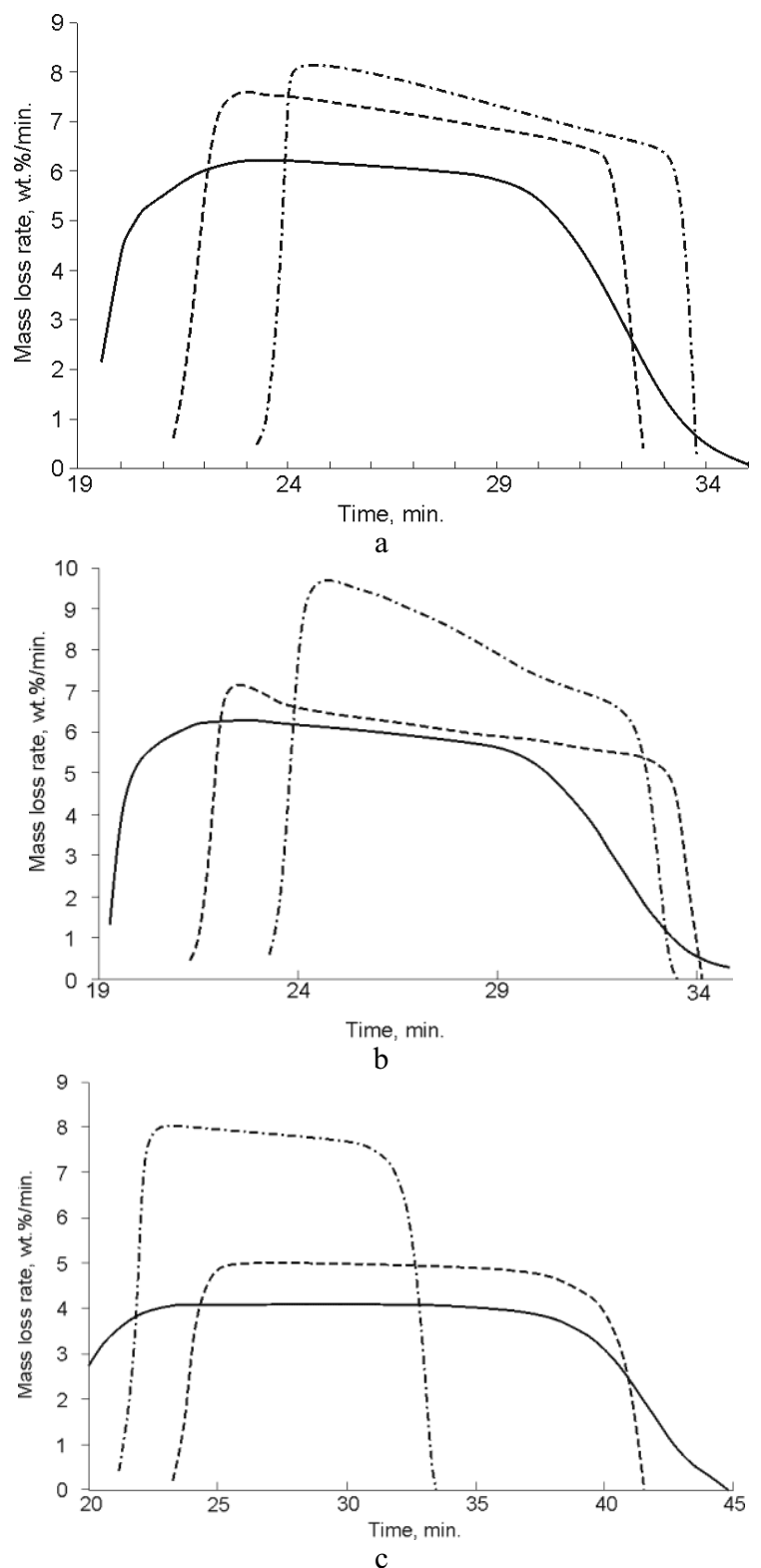

Figure 1. TG-curves for chars of anthracite (a), bituminous coal (b) and lignite (c).

The increasing of air temperature in furnace the sample combustion time values decreases while mass loss rate and carbon oxidation reaction rate increase. According to Arrhenius equation [6] the fuel mass loss rate during heterogeneous reactions are described by following equation: 


$$
v=A_{0} \exp \left(-E_{\mathrm{a}} / R T\right) f(X),
$$

here $v$ is the mass loss rate, $\mathrm{kg} / \mathrm{s} ; A_{0}-$ frequency factor, $\mathrm{kg} / \mathrm{s} ; E_{\mathrm{a}}-$ activation energy, $\mathrm{J} / \mathrm{mole}$; $R$ - gas constant, $\mathrm{J} /(\mathrm{kg} \mathrm{K}) ; T$ - temperature, $\mathrm{K} ; f(X)$ - kinetic function.

Three kinetic models were used in current work to define activation energy and frequency factor. It's volumetric model, shrinking-core model and random pore model which are represented by equations 2,3 and 4, respectively:

$$
\begin{gathered}
f(X)=(1-X), \\
f(X)=(1-X)^{2 / 3}, \\
f(X)=(1-X)(1-\psi \ln (1-X))^{0.5} .
\end{gathered}
$$

Based on the equation 1 with application of equations 2-4 in turn the activation energy and frequency factor values were defined for carbon oxidation reaction of coal char in air medium in temperature range $1000-1200{ }^{\circ} \mathrm{C}$. Reaction time was defined as difference between time moment with maximal mass loss rate and minimal time with mass loss rate less or equal than 0,01 from maximal value. The mass loss rates values are given in table 2 based on experimental data.

Table 2. Average mass loss rate.

\begin{tabular}{c|c|c|c}
\hline \multirow{2}{*}{ Coal char sample } & \multicolumn{3}{|c}{ Mass loss rate, $\mathbf{~} / \mathbf{s}$, at temperature } \\
\cline { 2 - 4 } & $\mathbf{1 0 0 0}^{\circ} \mathbf{C}$ & $\mathbf{1 1 0 0}^{\circ} \mathbf{C}$ & $\mathbf{1 2 0 0}^{\circ} \mathbf{C}$ \\
\hline Anthracite & 1.393 & 1.900 & 1.940 \\
Bituminous coal & 1.366 & 1.711 & 1.975 \\
Lignite & 0.946 & 1.538 & 1.958 \\
\hline
\end{tabular}

Comparison of mass loss rates at different temperatures shows that they are close to each other at $1200{ }^{\circ} \mathrm{C}$ while at 1000 and $1100{ }^{\circ} \mathrm{C}$ they are significantly different. This may be the caused by influence of diffusion on process kinetics at high temperatures.

Obtained activation energy and frequency factor values (table 3) for studied solid fuel samples and are in good correspondence with literature data for high and low-grade coals $[1,7]$. Activation energy dependence on fixed carbon content in initial fuel for all studied models are given in fig. 2 .

Table 3. Kinetic constants for coal char combustion in air medium.

\begin{tabular}{l|ccc|ccc}
\multirow{2}{*}{ Model } & \multicolumn{3}{|c|}{ Activation energy, $\mathbf{k J} / \mathbf{m o l e}$} & \multicolumn{3}{c}{ Frequency factor, 1/s } \\
\cline { 2 - 7 } Sample & VM & SCM & RPM & VM & SCM & RPM \\
\hline Anthracite & 12.93 & 40.43 & 53.49 & $4.01 \mathrm{E}+06$ & $2.72 \mathrm{E}+17$ & $3.14 \mathrm{E}+20$ \\
\hline Bituminous & 21.63 & 36.68 & 50.06 & $1.16 \mathrm{E}+11$ & $7.68 \mathrm{E}+15$ & $1.46 \mathrm{E}+19$ \\
\hline Lignite & 23.76 & 28.60 & 26.38 & $1.15 \mathrm{E}+12$ & $5.32 \mathrm{E}+11$ & $2.27 \mathrm{E}+10$ \\
\hline
\end{tabular}

Kinetic constant value analysis shows that activation energy and frequency factor values decreases with fixed carbon content in fuel for volumetric and shrinking core models. For random pore model the kinetic constant values are close to each other for all samples. Activation energy values varies in the range of $23-28 \mathrm{~kJ} / \mathrm{mole}$. This indicates that mechanism of reaction inside pores better describes processes in coal char. Bond energy between atoms in carbonaceous matrix for coals with different level of metamorphism. In anthracite and bituminous coal the inertinite phase prevails while for lignite the vitrinite with low bond energy prevails. As long as activation energy is integral parameter it may be lower for anthracite because nearly all bonds were saved because of volatile matter low content while for bituminous coal the weakest bonds are removed together with devolatiliztion products. 


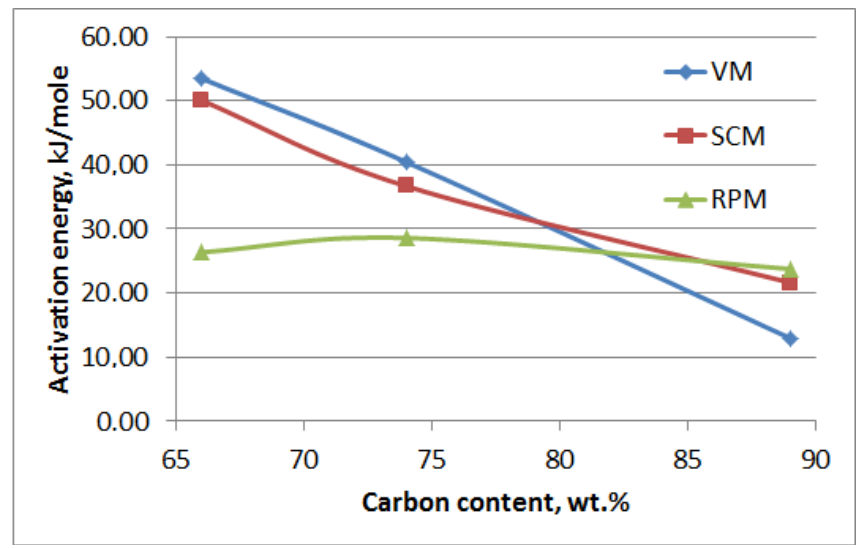

Figure 2. Activation energy dependence on fixed carbon content in initial fuel.

\section{Conclusion}

The oxidation process of anthracite, bituminous coal and lignite of Kuznetsk and KanskAchinsk deposits was studied via STA DSC Netzsch Jupiter 449 F3. The measurements were carried out in air at temperatures of 1000,1100 and $1200{ }^{\circ} \mathrm{C}$. The oxidation rate values tend to increase with increasing of temperature. Based on experimental results the activation energy and frequency factor were defined using $1^{\text {st }}$ order Arrhenius equation with three submodels. The highest preciseness was obtained for random pore submodel. The activation energy tend to decrease with fixed carbon content in initial coal char sample.

\section{References}

1. G.L. Manjunath and R.R. Nair, Int. J. Coal Geol. 141, 13 (2015)

2. D.G. Roberts, E.M. Hodge and D.J. Harris, Energy Fuels 24, 5300 (2010)

3. A.G. Korotkikh, K.V. Slyusarskiy and A.A. Ditts, Russ. J. Chem. Phys. 10, 576 (2016)

4. K. Larionov, I. Korjashov, S. Jankovskij, V. Gubin, A. Zenkov, MATEC Web of Conf. 37, 01030 (2015)

5. N.M. Laurendeau, Prog. Energ. Combust. 4, 221 (1978)

6. M.F Ifran, M.H. Chakrabarti and K. Kusakabe, Can. J. Chem. Eng. 91, 1936 (2013)

7. T. Maffei, R. Khatami, S. Pierucci, T. Faravelli, E. Ranzi and Y.A. Levendis, Combust. Flame 160, 2559 (2013) 